\title{
Rupture of suppurated liver hematoma into the anterior abdominal wall in a patient with Rendu-Osler-Weber syndrome
}

\section{Rotura de hematoma hepático supurado en la pared abdominal anterior en una paciente con síndrome de Rendu-Osler-Weber}

Igor Petrovic ${ }^{1}$, Goran Pavlek', Marijan Romic ${ }^{1}$, Dora Grgic ${ }^{2}$, and Ivan Romic ${ }^{*}$
${ }^{1}$ Department of Surgery; ${ }^{2}$ Department of Gastroenterology. University Hospital Centre Zagreb, Zagreb, Croatia

\begin{abstract}
We report a case of ruptured liver hematoma as a result of suppurated arteriovenous malformation (AVM) in a patient with Rendu-Osler-Weber (ROW) syndrome. The patient presented with unexplained fever and upper right abdominal pain associated with microcytic anemia. A computed tomography scan revealed increasing subcapsular liver hematoma and features of liver abscess. Intraoperatively, a left liver hematoma mixed with pus was found that was attached to the anterior abdominal wall. Surgery included left lateral bisegmentectomy, while pathohistological analysis showed AVM and genetic tests confirmed ROW. This is the first such life-threatening surgical case of ROW complication reported in the scientific literature.
\end{abstract}

Key words: Rendu-Osler-Weber syndrome. Liver abscess. Liver rupture. Hereditary telangiectasia.

\section{Resumen}

Reportamos el caso de una paciente con síndrome de Rendu-Osler-Weber y rotura de un hematoma hepático supurado como resultado de una malformación arteriovenosa. La paciente presentó fiebre inexplicable y dolor abdominal superior derecho asociado con anemia microcítica. La tomografía computarizada reveló un aumento del hematoma hepático subcapsular y las características del absceso hepático. Durante la cirugía se encontró un hematoma hepático izquierdo mezclado con pus que estaba unido a la pared abdominal anterior. La intervención incluyó bisegmentectomía lateral izquierda. El análisis histopatológico mostró malformación arteriovenosa y las pruebas genéticas confirmaron el síndrome de Rendu-Osler-Weber. Este es el primer caso quirúrgico potencialmente mortal de complicación de síndrome de Rendu-Osler-Weber reportado en la literatura científica.

Palabras clave: Síndrome de Rendu-Osler-Weber. Absceso hepático. Rotura del hígado. Teleangiectasia hereditaria.

\section{Introduction}

Hereditary hemorrhagic telangiectasia (HHT), also called Rendu-Osler-Weber (ROW) disease, is a genetic autosomal dominant disorder characterized by vascular malformations (VM) which are affecting the skin, mucosal membranes, and multiple internal organs. The reported incidence is estimated to be 1-2 /100,000; however, HHT is considered to be an underdiagnosed entity since many cases remain asymptomatic for the whole life'.

\section{Correspondence:}

*Ivan Romić

Kispaticeva, 12

Date of reception: 16-04-2020

C.P. 10000 , Zagreb, Croatia

E-mail: i.romic@gmail.com
Cir Cir. 2020;88(S2):66-70

Contents available at PubMed www.cirugiaycirujanos.com
of the CC BY-NC-ND license (http://creativecommons.org/licenses/by-nc-nd/4.0/) 
VM may include the whole spectrum of manifestation from small telangiectases to bigger arteriovenous malformations (AVM) with shunts, so symptomatology is also various and can be more or less significant depending on involved organs and size of VM.

Due to its rarity, etiology and pathogenesis are still not completely investigated, but studies revealed that gene mutation (called endoglin and ACVRL) leads to systemic fibrovascular dysplasia due to aberrant endothelial cell responses. Consequently, defects in the vascular walls of the blood vessels develop, making them prone to disruptions ${ }^{2}$.

The diagnosis is based on the Curacao criteria: a positive family history, epistaxis, mucocutaneous telangiectasias, and visceral organ involvement.

Epistaxis and mucocutaneous telangiectasias are the most common clinical manifestations which are typically seen (in $90 \%$ ) on the lips, buccal mucosa, and fingertips, while $75 \%$ of the patients have small telangiectasias in upper gastrointestinal (Gl) mucosa of which only $30 \%$ will eventually suffer from GI bleeding. The onset of symptoms is usually in the third decade of life, but it is reported in all age groups ${ }^{2,3}$.

Pulmonary involvement occurs in $30 \%$ of patients due to AVM, causing dyspnea, fatigue, and cyanosis. In the treatment of epistaxis and digestive manifestations, endoscopic or surgical intervention may be indicated. Less common, brain and genitourinary involvement are registered.

On the other hand, recent studies, based on more specific imaging tests, report that liver involvement in $\mathrm{HHT}$ is seen in around $75 \%$ of patients of which are only $8 \%$ of patients symptomatic mostly due to the involvement of systemic vasculature in the liver that leads to a high cardiac output state. At the same time, pulmonary shunts serve as right-to-left shunts, and this raises the risk of hypoxemia or paradoxical embolism and septic thrombi ${ }^{4}$.

Other manifestations include biliary ischemia which may lead to cholangitis, liver fibrosis, cirrhosis, or liver necrosis, as well as portal hypertension with hepatoencephalopathy in portovenous shunts. Less often, a complication of larger AVMs is a rupture with more or less significant bleeding that can be fatal if free intraperitoneal bleeding occurs.

The vascular liver malformations include lesions ranging from small asymptomatic telangiectases to larger AVM, leading to hemodinamically significant vascular shunts.

Most common vascular communications are arteriovenous shunts (hepatic artery to hepatic vein, type 1), while portal vein to hepatic vein (portovenous, type 2) and hepatic artery to portal vein (arterioportal, type 3) shunts are seen less commonly ${ }^{5,6}$.

Symptomatology is usually nonspecific, and patient complains are related to abdominal angina, weight loss, hepatomegaly, or weakness. With the progression of liver damage, jaundice, ascites, febrile episodes, peripheral edema, and anemia occurs.

Diagnosis of liver involvement is confirmed by Doppler ultrasonography or computed tomography (CT). The typical findings are intrahepatic hypervascularization, enlarged common hepatic artery, and nodular regenerative hyperplasia ${ }^{7}$.

Most symptoms and organ disorders are chronic and progressive, while urgent conditions are not typical presentation. The main indication for hospitalization is anemia that requires blood transfusions which are usually caused by occult Gl bleeding or by a combination of multiple bleedings from mucocutaneous telangiectases.

\section{Case presentation}

A 60-year-old woman with a 40 years history of ROW syndrome was referred to our institution due to unexplained fever and lower left abdominal pain associated with significant weight loss in the past 2 months. CT abdominal scan 3 years before surgery showed 2 older liver hematomas in the $2^{\text {nd }}$ and $3^{\text {rd }}$ liver segment measuring $5.8 \mathrm{~cm}$ and $3.5 \mathrm{~cm}$. The previous findings showed non-complicated lung hamartoma and small non-bleeding stomach telangiectases.

On taking a detailed history, we found that the patient, in the past 3 months, had three recurrent episodes of unexplained fever that lasted for around 10 days each month. Fevers were up to $39^{\circ} \mathrm{C}$ and associated with chills and shivering. The patient also complained of the right upper abdominal pain, weight loss of $21 \mathrm{~kg}$ in 2 months, and generalized weakness, often epistaxes and black stool color.

During pre-operative hospitalization, the patient was given 4 units of packed red blood cells in $24 \mathrm{~h}$, but despite, this hemoglobin count was continuously under 75 $\mathrm{g} / \mathrm{dl}$. The patient received intravenous antibiotics (meropenem), fluid replacement, and antiacid therapy. Besides anemia, the laboratory workup revealed elevated inflammatory markers and slightly elevated liver markers. CT scan revealed hepatomegaly with predominantly enlarged left liver lobe and a progression in size of subcapsular liver hematoma which was now $7.9 \times 5.2$ $\mathrm{cm}$ in the left lateral liver section and seemed to rupture 
into anterior abdominal wall (Fig. 1). No active intraabdominal bleeding was detected. During the admission, the patient was febrile and had stable vital signs.

Due to non-improving red blood count and progression in the size of liver hematoma with signs of inflammatory intra-abdominal process, the surgical procedure was indicated. Intraoperatively, a left liver lobe hematoma sized $10 \mathrm{~cm}$ was found that was attached to the anterior abdominal wall. After separating the liver from the abdominal wall, an abscess and continuous bleeding from non-specific liver lesion were found (Fig. 2). Also, enlarged common hepatic artery was detected with $1 \mathrm{~cm}$ in diameter (Fig. 3). Hemostasis was performed and abscess drained, after which star-like liver defect was noticed that involved $2^{\text {nd }}$ and partially $3^{\text {rd }}$ liver segment, so left lateral bisegmentectomy was performed (Fig. 4). Furthermore, enlarged common hepatic artery was detected with $1 \mathrm{~cm}$ in diameter. The patient had an uneventful postoperative course, inflammatory markers normalized, and anemia resolved over the next 2 weeks.

Histopathological examination showed a star-like liver defect, filled with pus, granulcoytes and foreignbody giant cells surrounded with fibrous tissue. In addition, abnormal direct communications between hepatic arterial branches and ectatic sinusoids were noted which was suggestive of ruptured AV malformation associated with liver abscess.

\section{Discussion}

Hepatic lesions in HHT are unpredictable but frequently progressive and lead to chronic liver damage. Liver-related surgical urgencies are not usual, but in all patients with $\mathrm{HHT}$, the clinician should be aware of possible acute or subacute complications since these may range from no-impact to even life-threatening ones.

Serious acute complications include bile duct ischemia which can lead to massive bile duct necrosis and necrotizing cholangitis with possible acute liver failure; hemobilia secondary to rupture of AVM in the biliary tree or free intraperitoneal rupture of $\mathrm{AVM}^{8}$. In the literature, there are many reported cases of brain abscesses due to paradoxal septic embolization through pulmonary AV shunts; however, liver abscesses are considered to be unusual complication of ischemic cholangitis ${ }^{9}$. Rupture of liver AVM with active bleeding is rare as well, and most ruptures occur into the biliary tree, while only larger peripheral lesions rupture into the peritoneal cavity and may lead to fatal consequences.
Now, we can add another liver-related complication since our case is the first one describing a liver defect that was synchronously filled with pus and hematoma with active bleeding after separating the involved part of the liver from the anterior abdominal wall. These features and patohistologic examination indicate ruptured suppurative liver AVM that was sealed off with parietal peritoneum and clinically presented with persistent mycrocytic anemia and intermittent fever. Fever is an expected sign of liver abscess and anemia was obviously caused by enlarging liver hematoma, and in a specific moment that it became refractor to blood transfusions.

This required repeated CT scans and urgent surgical procedure to prevent possibly fatal free intraperitoneal bleeding.

We could explain this clinical scenario with two mechanisms. First, the primary event may have been the development of liver abscess that consequently caused erosion of liver AVM which then ruptured into the anterior abdominal wall. The etiology of a liver abscess may have been ischemic cholangitis or septic thrombi. Second explanation is the rupture of AVM as a primary incident which caused subcapsular liver hematoma that became subsequently inflamed with the development of abscess that spreads into the anterior abdominal wall.

In every case, concomitant liver abscess and AVM with surrounding hematoma in patients with HHT have never been reported, and our case report highlights the necessity of detailed pre-operative and intraoperative planning. In these situations, the surgeon must have in mind the risk of major intraoperative bleeding and be sceptic about pre-operative imaging tests which may indicate stabile intraparenchymal hematoma or an abscess which then turns to involve liver surface and be attached to the parietal peritoneum. This may complicate the expected intraoperative course and necessitates high surgical experience in the management of liver lesions and liver-related bleeding. In general, for patients with asymptomatic liver involvement, no treatment is currently recommended. Symptomatic patients are treated with intensive medical treatment depending on the predominant clinical presentation. The most common complication, high output heart failure, responds mostly to intensive medical therapy (correction of anemia, salt restriction, diuretics, and antihypertensive agents) ${ }^{10}$.

Portal hypertension and its consequences should be treated as recommended in other types of cirrhosis, and ischemic cholangitis is treated with wide-spectrum 


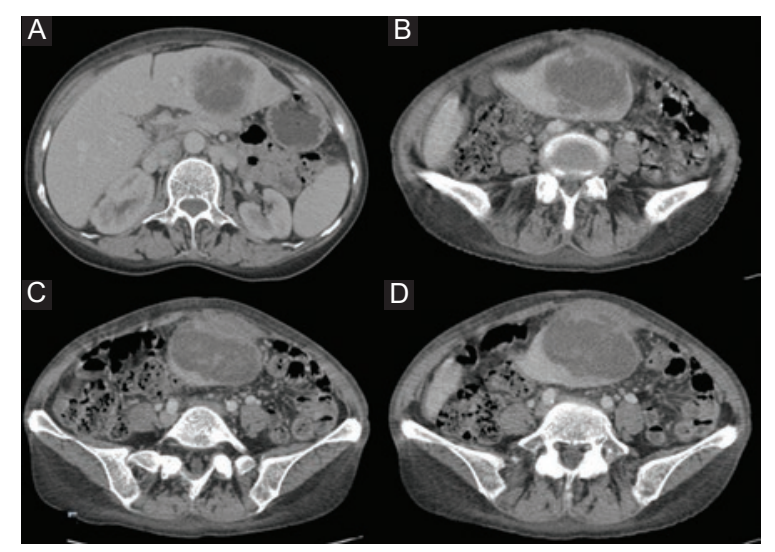

Figure 1. A-D: Computed tomography scan showing hepatomegaly with predominantly enlarged left liver lobe, and a subcapsular liver hematoma with surrounding abscess sized $7.9 \times 5.2 \mathrm{~cm}$ located in the left lateral liver section that ruptured into anterior abdominal wall; the perforation is covered so there is no free intra-abdominal bleeding or fluid.

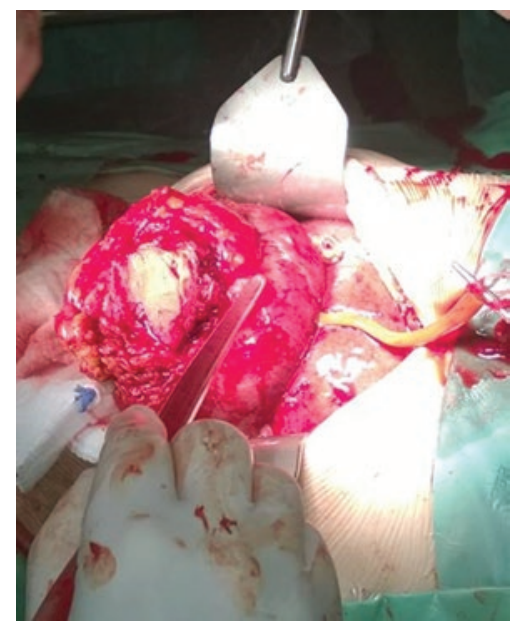

Figure 2. Intraoperative photograph of liver surface after separating it bluntly from the anterior abdominal wall where liver defect (ruptured hematoma) covered with gauze is seen.

intravenous antibiotics, but this complication generally has a poor prognosis.

Invasive palliative treatments are indicated in patients with complicated liver AVMs failing to respond to conservative treatment and a progressive worsening of their clinical condition. Orthotopic liver transplantation has been proposed as the only definitive curative option for hepatic VMs in HHT. The main indications considered for liver transplantation are high output cardiac failure, acute biliary/hepatic necrosis.

Transarterial embolization of liver VMs is a palliative, procedure that may be used as a last resort in patients who are not candidates for liver transplantation but

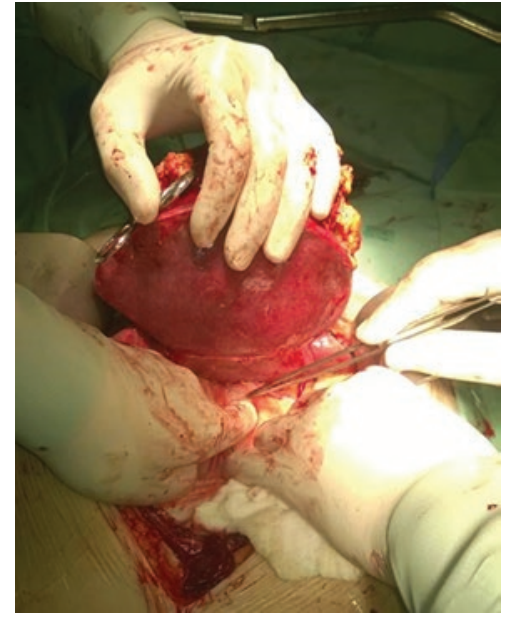

Figure 3. After elevation of the right lobe and porta dissection, a dilated hepatic artery was observed (the diameter was $18 \mathrm{~mm}$ ).

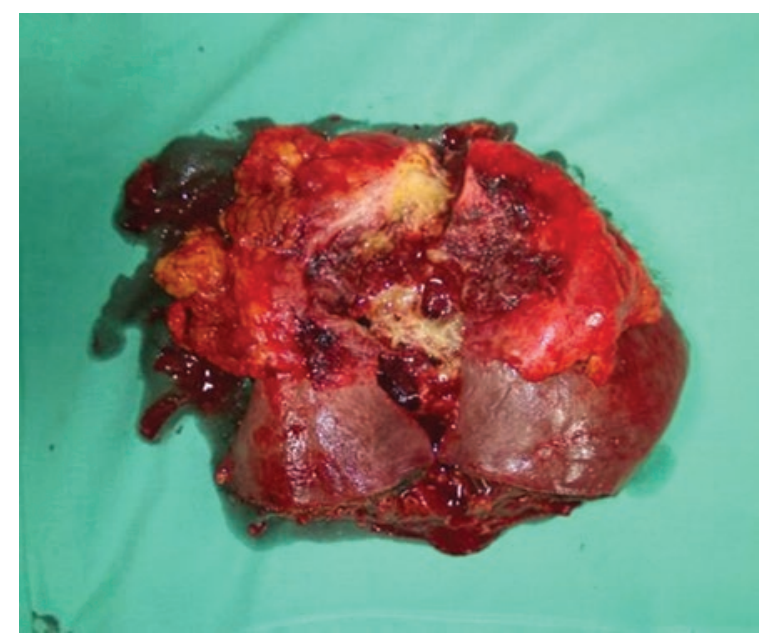

Figure 4. Specimen after the right hepatectomy showing star such as defect in the anterior surface with abscess cavity, fibrous capsule, and disrupted arteriovenous malformation.

should be avoided when possible due to the high complication rate. Another treatment option is systemic bevacizumab which recently showed promising results for AVMs.

Some authors suggest that patients with HHT should receive antibacterial prophylaxis for procedures placing them at risk for bacteremia to prevent possible embolic abscesses ${ }^{10,11}$. Major liver resections are not standard therapy for HHT complications, but these are indicated in cases of surgical emergencies such as bleeding from the ruptured lesion or hepatic abscess with sepsis. Liver transplantation remains the therapeutic option of choice, and bevacizumab may be useful as bridging therapy for patients who are 
awaiting transplantation or an alternative for patients who are not eligible for transplantation ${ }^{11}$.

\section{Conclusion}

Liver involvement in ROW is seen in the majority of the patient, but only around $8 \%$ of them present with symptoms mostly caused by high cardiac output as a consequence of pathologic systemic vasculature in the liver. Liver-related symptoms include cholangitis and complications related to AVM enlargement and rupture which more often intrabilliary than intraperitoneal, but our case revealed another possible scenario with synchronous development of abscess and ruptured AVM that was sealed off with parietal peritoneum and led to subacute anemia, pain, and intermittent fevers. Due to the covered rupture and appropriate surgical procedure, the patient survived and recovered quickly. It is very important for the clinician to recognize the signs and symptoms of lifethreatening liver-related incidents in ROW so that surgical management can be performed successfully and on time.

\section{Conflicts of interest}

The authors declare that they have no conflicts of interest.

\section{Funding}

The authors declare that this article was not funded.

\section{Ethical disclosures}

Protection of human and animal subjects. The authors declare that no experiments were performed on humans or animals for this study.

Confidentiality of data. The authors declare that they have followed the protocols of their work center on the publication of patient data.

Right to privacy and informed consent. The authors have obtained the written informed consent of the patients or subjects mentioned in the article. The corresponding author is in possession of this document.

\section{References}

1. Martini GA. The liver in hereditary haemorrhagic teleangiectasia: an inborn error of vascular structure with multiple manifestations: a reappraisal. Gut. 1978;19:531-7.

2. Buscarini E, Leandro G, Conte D, Danesino C, Daina E, Manfredi G, et al. Natural history and outcome of hepatic vascular malformations in a large cohort of patients with hereditary hemorrhagic teleangiectasia. Dig Dis Sci. 2011;56:2166-78.

3. Boza JC, Dorn TV, De Oliveira FB, Bakos RM. Case for diagnosis. An Bras Dermatol. 2014;89:999-1001.

4. Garg N, Khunger M, Gupta A, Kumar N. Optimal management of hereditary hemorrhagic telangiectasia. J Blood Med. 2014;5:191-206.

5. Govani FS, Shovlin CL. Hereditary haemorrhagic telangiectasia: a clinical and scientific review. Eur J Hum Genet. 2009;17:860-71.

6. Draghi F, Presazzi A, Danesino GM, De Matthaeis N, Rapaccini GL, Danesino C. Hepatic sonography in patients with hereditary hemorrhagic telangiectasia hospitalized for epistaxis. J Ultrasound. 2012;15:164-70.

7. Lee JH, Lee YS, Kim PN, Lee BH, Kim GW, Yoo HW, et al. Osler-Weber-Rendu disease presenting with hepatocellular carcinoma: radiologic and genetic findings. Korean J Hepatol. 2011;17:313-8.

8. Swanson DL, Dahl MV. Embolic abscesses in hereditary hemorrhagic telangiectasia. J Am Acad Dermatol. 1991;24:580-3.

9. Mclnroy $B$, Zajko AB, Pinna AD. Biliary necrosis due to hepatic involvement with hereditary hemorrhagic telangiectasia. AJR Am J Roentgenol. 1998;170:413-5.

10. Blewitt RW, Brown CM, Wyatt JI. The pathology of acute hepatic disintegration in hereditary haemorrhagic telangiectasia. Histopathology. 2003;42:265-9.

11. Thevenot $T$, Vanlemmens $C$, Di Martino V, Becker MC, Denue PO, Kantelip B, et al. Liver transplantation for cardiac failure in patients with hereditary hemorrhagic telangiectasia. Liver Transpl. 2005;11:834-8. 